EGU2020-15774, updated on 30 Apr 2020

https://doi.org/10.5194/egusphere-egu2020-15774

EGU General Assembly 2020

(c) Author(s) 2020. This work is distributed under

the Creative Commons Attribution 4.0 License.

\title{
Arsenic and Boron Hydrogeochemistry behaviour during Managed Aquifer Recharge Operations.
}

\author{
Esteban Caligaris and Rudy Rossetto \\ Institute of Life Sciences, Scuola Superiore Sant'Anna, Pisa, Italy (e.caligaris@santannapisa.it)
}

The Cornia Valley aquifer system (Tuscany, Italy) is the main source for irrigation, industrial purposes, and for potable water supply for the zone and the Elba island. Sixty years of its overexploitation caused a remarkable potentiometric drawdown accompanied with a wide seawater intrusion and a severe degradation of the quality of the groundwater (Rossetto et al., 2018; 2019).

In the early 2000s, extensive research regarding anomalous high concentrations of Boron in the Cornia Valley was carried out. These studied the hydrochemistry of the area, determining also anomalous high concentrations of Arsenic (Pennisi et al., 2009). In addition, one of the biggest schemes treating Arsenic for drinking water started operating with other two plants for Boron (Comune di Suvereto, 2013). Furthermore, in 2015 the LIFE REWAT project was started in order to set a strategy to recover and improve the availability of water in the area through a series of technical and social interventions (Rossetto et al., 2018).

Within LIFE REWAT, Managed Aquifer Recharge (MAR) was identified as a solution to counterbalance the stressed hydrologic system. Thus, a pilot MAR scheme infiltrating harvested rainwater from the Cornia River was implemented. It is provided by a hi-tech high-frequency automated and remotely controlled system for operating the plant and monitoring water quantity and quality. This system is supported by the data gathered from different sensors installed in the area, recording into a database. Additionally, discrete groundwater sampling takes place monthly (Rossetto et al., 2018; 2019).

The database contains recordings from two consecutive hydrological years. The first year measurements and samplings were done under natural recharge conditions, while during the second year the MAR scheme was under operation. This initial data provides insights on concentration variations of Boron and Arsenic after one-year operation of the MAR scheme. However, the main processes involved still need to be understood. Therefore, long-term and shortterm dedicated field experiments are designed to analyse the induced variations. This work presents a model based hydrogeochemical approach for the behaviour analysis of these elements under MAR operations to determine the transiency of these concentration changes.

\section{Acknowledgements}


This paper is presented within the framework of MARSoluT ITN (www.marsolut-itn.eu), a Marie Skłodowska-Curie Actions (MSCA) Innovative Training Network (ITN) funded by the European Commission (Grant Agreement 814066).

\section{References}

Comune di Suvereto (2013). Impianti per Arsenico e Boro in Val di Cornia. http://www.comune.suvereto.li.it/moduli/output_immagine.php?id=709 [Webpage. Italian. Accessed the 14/01/2020]

Pennisi, M., Bianchini, G., Kloppmann, W., \& Muti, A. (2009). Chemical and isotopic (B, Sr) composition of alluvial sediments as archive of a past hydrothermal outflow. Chemical Geology, 266(3-4), 114-125.

Rossetto, R., De Filippis, G., Piacentini, S. M., Matani, E., Sabbatini, T., Fabbrizzi, A., ... \& Menonna, V. (2018). Using flood water in Managed Aquifer Recharge schemes as a solution for groundwater management in the Cornia valley (Italy). Geophysical Research Abstracts (Vol. 20).

Rossetto, R., De Filippis, G., Piacentini, S. M., Neri, S., Continanza, D., Brilli, M., ... \& Lazzaroni, F. (2019). Increasing reliability and safety of Managed Aquifer Recharge schemes for tackling water scarcity. Geophysical Research Abstracts (Vol. 21). 